\title{
Preparation of Magnetic Hybrid Microspheres with Well-Defined Yolk-Shell Structure
}

\author{
Yuan Zhao, ${ }^{1,2}$ Tao Chen, ${ }^{1,2}$ Shaofa Sun, ${ }^{1,2}$ and Long Zhao ${ }^{1}$ \\ ${ }^{1}$ Hubei Collaboration Innovative Center for Nonpower Nuclear Technology, Hubei University of Science and Technology, \\ Xianning 437100, China \\ ${ }^{2}$ School of Nuclear Technology and Chemistry and Biology, Hubei University of Science and Technology, Xianning 437100, China \\ Correspondence should be addressed to Tao Chen; taochen518@163.com
}

Received 15 June 2016; Revised 6 September 2016; Accepted 8 September 2016

Academic Editor: Peter Majewski

Copyright (C) 2016 Yuan Zhao et al. This is an open access article distributed under the Creative Commons Attribution License, which permits unrestricted use, distribution, and reproduction in any medium, provided the original work is properly cited.

\begin{abstract}
A facile and efficient route was reported to prepare a kind of yolk-shell magnetic hybrid microspheres by suspension polymerization and calcinations method. The morphology, structure, and composition of the magnetic microspheres were characterized by FTIR, XRD, TEM, SEM, and TGA analysis. The vibrating-sample magnetometry (VSM) results clearly showed that the magnetic particles were superparamagnetic with saturation magnetization of $32.82 \mathrm{emu} / \mathrm{g}$ which makes the microcomposites easily controlled by an external magnetic field. The results revealed that the magnetic hybrid microspheres might have important applications in magnetic bioseparation and drug delivery.
\end{abstract}

\section{Introduction}

In recent years, magnetic particles have been paid considerable attention due to their superparamagnetic properties and potential applications, for example, magnetic bioseparation $[1,2]$, drug delivery $[3,4]$, magnetorheological fluid [5], magnetic resonance imaging contrast enhancement $[6,7]$, targeted drug [8], gene separation from biochemical products and cells [9], microwave absorption [10], high saturation magnetization, high magnetic susceptibility, biocompatibility, and low toxicity. Therefore, more and more researchers have focused on the fascinating feature of targeting [11-13]. However, because bare magnetic particles are liable to aggregation and rapid biodegradation when they are exposed to a biological system, coupled with a limited carrying capacity, it is quite necessary to combine magnetic particles with other carriers to achieve targeted delivery efficiently [14-16].

Various inorganic and polymeric materials have been reported as carriers of magnetic materials [17-20]. Recently, polymers which could stabilize magnetic particles are receiving more and more attention. Polymers can increase repulsive forces more than surfactants. In addition, a polymer coating on the surface used for the designed purpose of a well-defined composite of materials and their dispersions offers a high potential of application in several fields [21-24]. There are mainly two methods to prepare $\mathrm{Fe}_{3} \mathrm{O}_{4} @$ polymer composite particles: first polymer coating $\mathrm{Fe}_{3} \mathrm{O}_{4}$ or modified $\mathrm{Fe}_{3} \mathrm{O}_{4}$ is used directly [25-27]; second $\mathrm{Fe}_{3} \mathrm{O}_{4}$ is first prepared by the coprecipitation of ferrous and ferric ions at the ratio of $1: 2$ in an alkaline medium and at the same time $\mathrm{Fe}_{3} \mathrm{O}_{4} @$ polymer is prepared, because $\mathrm{Fe}_{3} \mathrm{O}_{4}$ contains ferrous and ferric iron at this ratio $[28,29]$.

In this contribution, we report a simple and efficient route to prepare yolk-shell monodisperse superparamagnetic polymer@ $\mathrm{Fe}_{3} \mathrm{O}_{4}$ composite microspheres, using ferric ions as the only source of iron. Unlike traditional synthesis methods, we first prepare $\mathrm{Fe}(\mathrm{OH})_{3} @$ PMMA. Then, the magnetic hybrid microspheres were obtained by calcination". The well control of the calcination temperature contributes to getting well-defined yolk-shell magnetic hybrid microspheres. The unique advantage of the yolk-shell morphology lies in the presence of internal void space to accommodate the targeted drug.

\section{Experimental Details}

2.1. Materials. Methyl methacrylate (MMA, 99 wt.\%, Shanghai Chemical Reagent Company, China) was distilled under 

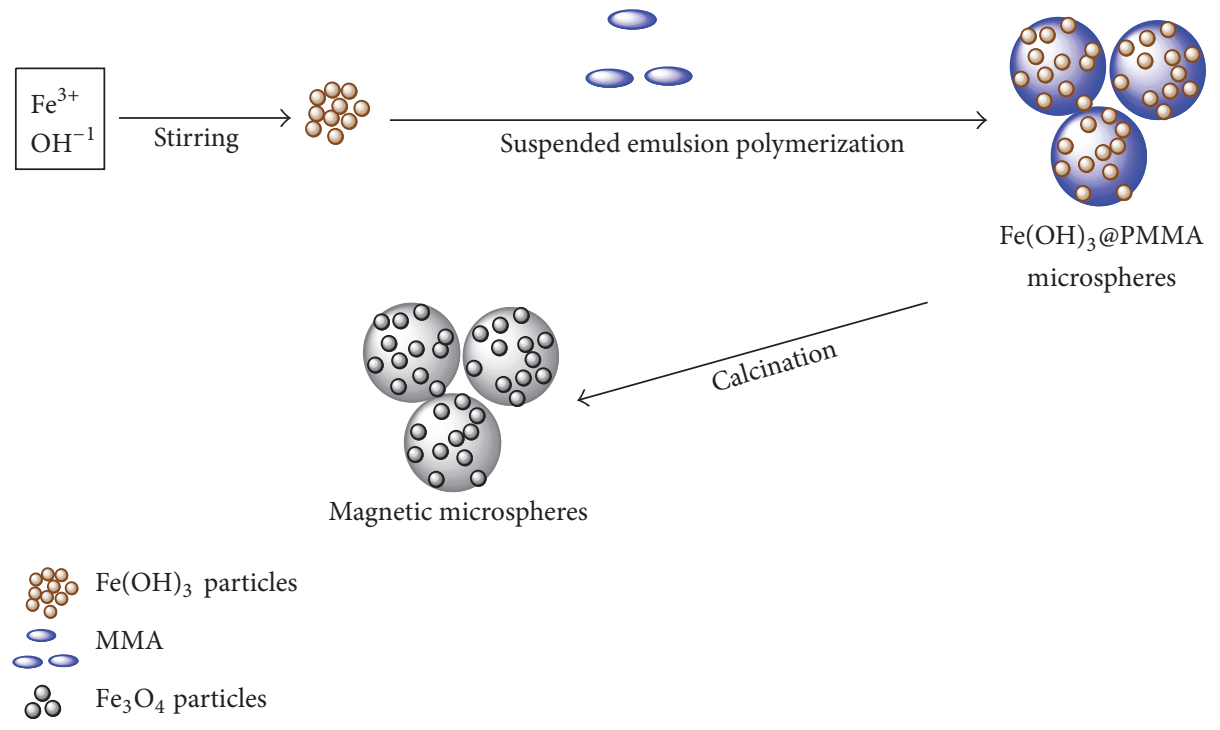

FIGURE 1: Schematic illustration of the synthesis process of magnetic microspheres.

reduced pressure before polymerization. Absolute ethanol was of reagent grade. Benzoyl peroxide (BPO) (97 wt.\%, Aldrich) was used as received. Poly(vinyl pyrrolidone) (PVP, K30) was purchased from Shanghai Chemical Regent Company, China. Ferric nitrate $\left(\mathrm{Fe}\left(\mathrm{NO}_{3}\right)_{3}\right)$, sodium hydroxide $(\mathrm{NaOH})$, and sodium dodecylbenzene sulfonate (SDBS) were purchased from Tianjin Guangfu Chemical Reagents Company, China. Water used throughout all experiments was distilled followed by deionization.

2.2. Preparation. The overall synthesis procedure and possible mechanisms for formation of the monodisperse magnetic hybrid microspheres were illustrated in Figure 1, and the detailed procedures are described as follows.

(1) Preparation of $\mathrm{Fe}(\mathrm{OH})_{3} @ P M M A$ Composite Microspheres. In a typical preparation procedure, $0.5 \mathrm{~g}$ SDBS and $80 \mathrm{~mL}$ deionized water were added into a $250 \mathrm{~mL}$ four-necked flask fitted with a condenser, coupled with a mechanical overhead stirrer, and at the same time inlet for nitrogen gas. $3 \mathrm{~mL} 1 \mathrm{M}$ $\mathrm{NaOH}$ and $1 \mathrm{~mL} 1 \mathrm{M} \mathrm{Fe}\left(\mathrm{NO}_{3}\right)_{3}$ were added in turns as the water was heated to $60^{\circ} \mathrm{C}$. Then, $5 \mathrm{~mL}$ methyl methacrylate was injected into the mixture above under continuous vigorously stirring. The initiator BPO $(0.15 \mathrm{~g})$ that dissolved in $20 \mathrm{~mL}$ deionized water was then added into the flask, and the flask was heated to $70^{\circ} \mathrm{C}$ gradually in an oil bath with stirring. The polymerization was maintained for $2 \mathrm{~h}$. The particles, which appear yellow in color, were centrifuged at $7000 \mathrm{rpm}$ for $5 \mathrm{~min}$, the supernatant was removed, and the pellet was resuspended in water. This wash process was performed three times. After the last wash, the supernatant was removed, and the pellet was dried under ambient conditions.

(2) Preparation of Magnetic Particles. The obtained Fe $(\mathrm{OH})_{3} @$ PMMA composite microspheres were heated to $350^{\circ} \mathrm{C}$ at a ramp rate of $100^{\circ} \mathrm{Ch}^{-1}$ under $\mathrm{N}_{2}$ atmosphere in a pipe furnace and kept at this temperature for $2 \mathrm{~h}$ to remove $\mathrm{CO}_{3}{ }^{2-}$ and water. Then, a kind of black powder was obtained from the crucible after calcinations [30]. A possible mechanism was that by calcination of PMMA@ $\mathrm{Fe}(\mathrm{OH})_{3}$ at $350^{\circ} \mathrm{C}$ for $3 \mathrm{~h}$ under $\mathrm{N}_{2}$ atmosphere, $\mathrm{Fe}_{2} \mathrm{O}_{3}$ nanoparticles were formed, and part of PMMA coating was carbonized. Then, the inner $\mathrm{Fe}_{2} \mathrm{O}_{3}$ NPs were reduced to $\mathrm{Fe}_{3} \mathrm{O}_{4}$ by the resulting outer carbon layers during the calcination process $[31,32]$.

2.3. Characterizations. A Hitachi S3400 SEM was used to determine the morphology and composition of the products with samples previously coated with gold via vapour deposition. TEM measurements were made on a Philips CM12 TEM/STEM with an accelerating voltage of $120 \mathrm{kV}$. XRD analysis was carried out on a D/Max 2500V/PC X-ray diffractometer using $\mathrm{Cu}(40 \mathrm{kV}, 30 \mathrm{~mA})$ radiation. FTIR spectroscopy was done in solid state on a Perkin Elmer Spectrum 100. TGA were performed on a TGA Q50 from TA Instrument using a temperature ramp from 30 to $600^{\circ} \mathrm{C}$ at $10^{\circ} \mathrm{C} / \mathrm{min}$ under nitrogen atmosphere. Specific surface area $\mathrm{N}_{2}$ adsorption measurements were performed on a Micromeritics ASAP 2010 V4 analyzer (Nor-mass, GA) and the data were subjected to the Brunauer-Emmett-Teller (BET) treatment. The magnetic properties were investigated with a BHV-55 vibrating-sample magnetometer (VSM) at room temperature.

\section{Results and Discussion}

3.1. FTIR Analysis. Figure 2 shows the infrared spectra of $\mathrm{Fe}(\mathrm{OH})_{3} @ \mathrm{PMMA}$ composite microspheres (a) and magnetic microspheres (b). The prominent bands in the FTIR spectrum (Figure 2(a)) were associated with the polymerization of the acrylic $\left(\mathrm{C}=\mathrm{O}\right.$ at $1728 \mathrm{~cm}^{-1},-\mathrm{CH}$ between 2840 and $2955 \mathrm{~cm}^{-1},-\mathrm{CH}_{2}$ at $1457 \mathrm{~cm}^{-1}$, and $\mathrm{C}-\mathrm{O}$ between 1082 and $1270 \mathrm{~cm}^{-1}$ ) $[28,33]$. As seen from Figure 2(b), the typical adsorption peaks of PMMA were weakened, which further demonstrated that PMMA template was mostly removed 


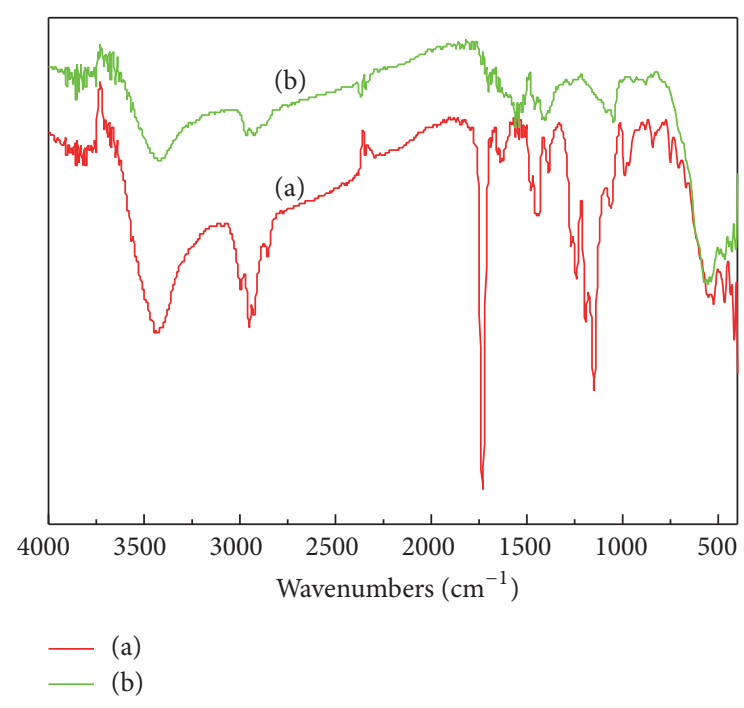

FIgURE 2: IR spectrum of (a) Fe(OH) $)_{3} @$ PMMA composite microspheres and (b) magnetic microspheres.

from the composite microspheres by means of calcination. And the adsorption centered at $580 \mathrm{~cm}^{-1}$ corresponding to the Fe-O vibration related to the magnetite phase $[34,35]$. The IR analysis provides some insights into the composition of the core and the composite.

3.2. Nanostructure and Component. The surface morphology and components of the prepared sample $\mathrm{Fe}(\mathrm{OH})_{3} @ P M M A$ were examined by SEM and EDS, respectively, as shown in Figures 3(a) and 3(b). The SEM image showed that the products were composed of some well monodispersed spheres with a coarse surface. As illustrated in Figure 3(b), EDS analysis indicated that, besides weak $\mathrm{Al}$ peaks, only $\mathrm{C}, \mathrm{Fe}$, and $\mathrm{O}$ were detected, which provides evidence for the presence of $\mathrm{Fe}(\mathrm{OH})_{3} @ \mathrm{PMMA}$ particles. Based on the above results, it has been confirmed that PMMA was hybridized with $\mathrm{Fe}(\mathrm{OH})_{3}$ [28].

TEM measurements could provide further insights into the morphology and structure of composite particles, and TEM images of resultant microspheres were shown in Figure 3(c). It shows that magnetic microspheres were of spherical shape with a particle size in the range of $150-300 \mathrm{~nm}$, and they have two phases $[31,36]$. The bright phase maybe is partly carbonized polymer and the dark phase is magnetic $\mathrm{Fe}_{3} \mathrm{O}_{4}$. Most interestingly, these composite particles have a novel yolk-shell morphology. Moreover, it is observed that very thin layer was facilely coated on the surface of $\mathrm{Fe}_{3} \mathrm{O}_{4} \mathrm{NPs}$ which maybe is partly carbonized PMMA [37]. It could be noted that the calcination temperature was controlled pretty well. Figure 3(d) shows the corresponding SAED pattern taken from the single sphere. The diffraction rings suggest that the magnetite spheres were polycrystalline, confirming that the sphere was composed of many small particles. From inside to outside, the rings can be indexed to (220), (311), (400), (422), and (440) planes of spinel $\mathrm{Fe}_{3} \mathrm{O}_{4}$, respectively. The magnetic hybrid microspheres are composed of the porous hollow spheres reported by Cheng et al. [36].
3.3. XRD Analysis. XRD measurement was an effective way to further investigate the presence of intercalation in composites. Figure 4 shows the X-ray diffraction pattern of $\mathrm{Fe}(\mathrm{OH})_{3} @ P M M A$ (a) and magnetic microspheres (b). Because of the high concentration of PMMA, there were no sharp diffraction peaks in the diffractogram of $\mathrm{Fe}(\mathrm{OH})_{3} @ P M M A$ microspheres, which could confirm their noncrystalline nature (Figure 4(a)). Based on Figure 4(b), characteristic diffraction peaks at $2 \theta$ of $30.2^{\circ}, 35.7^{\circ}, 43.3^{\circ}$, $57.2^{\circ}$, and $62.6^{\circ}$ were assigned to [220], [311], [400], [333], and [440] lattice planes of $\mathrm{Fe}_{3} \mathrm{O}_{4}$. On the basis of the analysis above, it was confirmed that magnetic microspheres were successfully prepared. XRD patterns of the magnetic hybrid microspheres indicate that all the characteristic peaks match well with the standard crystal phase of magnetite (JCPDS numbers 894319, 19-0629) [38, 39]. So the spinel structures of magnetite in the samples were retained. Moreover, the intensity of diffraction peaks for the magnetic composite microspheres became lower as the $\mathrm{Fe}_{3} \mathrm{O}_{4}$ content decreased [4]. XRD patterns revealed that $\mathrm{Fe}_{3} \mathrm{O}_{4}$ content significantly affected the characteristic peak intensities of the $\mathrm{Fe}_{3} \mathrm{O}_{4} /$ PMMA composite microspheres. PMMA had little influence because of its transparency over the $\mathrm{Fe}_{3} \mathrm{O}_{4}$ peak range.

3.4. Nitrogen Sorption Isotherm. The nitrogen adsorptiondesorption isotherms of $\mathrm{Fe}(\mathrm{OH})_{3} @ P M M A$ (a) and magnetic microspheres (b) were presented in Figure 5. It could be observed from Figure 5(a) that the sorption isotherm was of type III, which demonstrated that $\mathrm{Fe}(\mathrm{OH})_{3} @ P M M A$ nearly have no porous. After being calculated, the BET surface area increased from $3.19 \mathrm{~m}^{2} / \mathrm{g}$ to $32.98 \mathrm{~m}^{2} / \mathrm{g}$ and the sorption isotherm was of type IV (Figure 5(b)) and displayed an obvious hysteresis loop, which demonstrated that magnetic microspheres were typical porous materials. This may be explained by the fact that after calculating part of PMMA was carbonized and the BET surface area was increased [40]. Furthermore, the relatively large pore volume was $1.33 \mathrm{~cm}^{3} / \mathrm{g}$ by using the BET method, which could endow magnetic microspheres with large drug loading capacity.

3.5. TGA Analysis. The materials were quantified by TGA under nitrogen atmosphere. Figure 6 shows the TGA curves of $\mathrm{Fe}(\mathrm{OH})_{3} @ \mathrm{PMMA}$ composite microspheres and magnetic microspheres. After being calcined at $600^{\circ} \mathrm{C}$, the $\mathrm{Fe}(\mathrm{OH})_{3} @ \mathrm{PMMA}$ composite nanosphere sample lost 80.5\% of its weight in two steps (Figure 6(a)). The weight loss before $270^{\circ} \mathrm{C}$ can be assigned to the dehydration of $\mathrm{Fe}(\mathrm{OH})_{3}$. It was noted that the decomposition temperature of PMMA ranged from $270^{\circ} \mathrm{C}$ to $500^{\circ} \mathrm{C}$, and it was completely decomposed at $500^{\circ} \mathrm{C}$ [28]. Figure 5(a) exhibited the residual weight of about $19.5 \%$, which suggested that the content of PMMA was about $80.5 \%$ in the $\mathrm{Fe}(\mathrm{OH})_{3} @ \mathrm{PMMA}$ composite microspheres. Figure $6(\mathrm{~b})$ shows that magnetic microspheres begin to lose weight at $270^{\circ} \mathrm{C}$ and ended at $500^{\circ} \mathrm{C}$ and exhibited a residual weight of about $70.5 \%$. The result shows that most of the PMMA in the composite microspheres decomposed after being carbonized at $350^{\circ} \mathrm{C}$ for $2 \mathrm{~h}$, but there still have a small amount of residue PMMA [41]. 


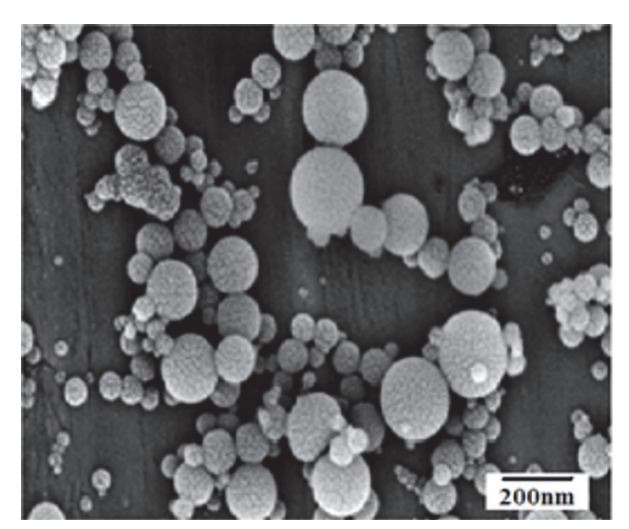

(a)

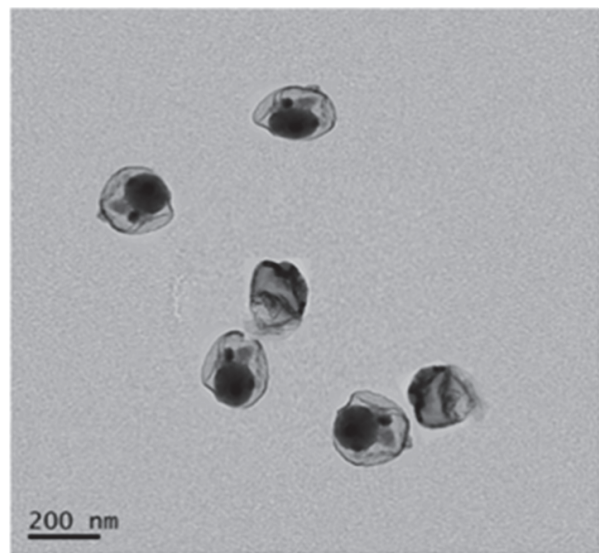

(c)

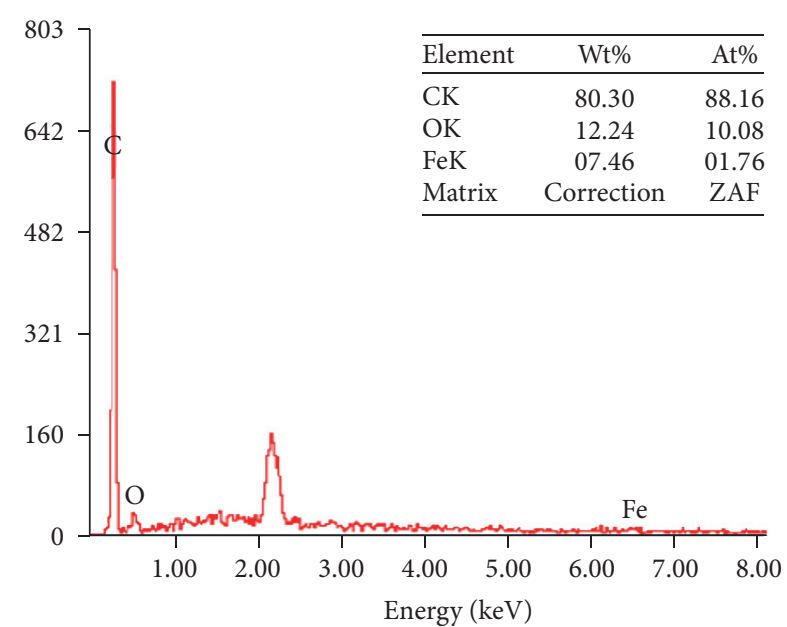

(b)

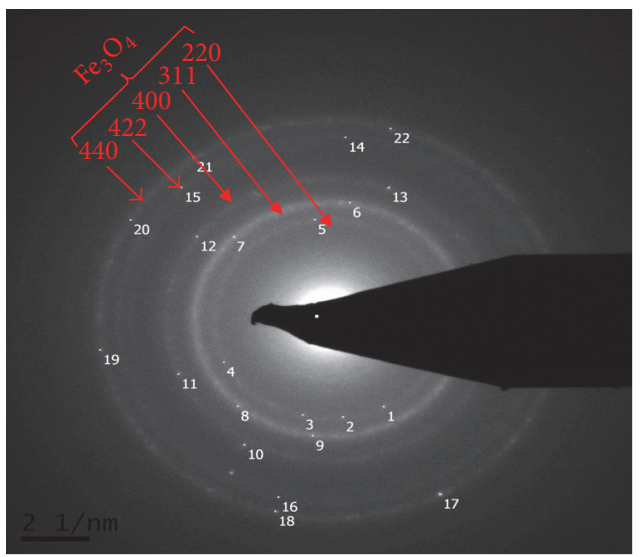

(d)

FIGURE 3: SEM image (a) and EDS spectrum (b) of Fe(OH) $)_{3} @ P M M A$ microspheres; TEM image (c) and single sphere SAED pattern (d) of magnetic microspheres.

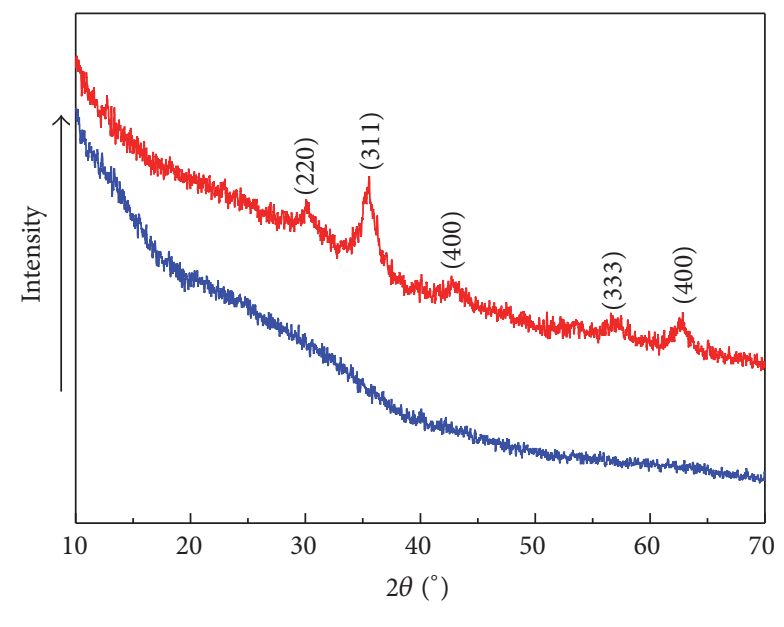

- (a)

(b)

FIgURE 4: XRD patterns of (a) $\mathrm{Fe}(\mathrm{OH})_{3} @ P M M A$ composite microspheres and (b) magnetic microspheres.

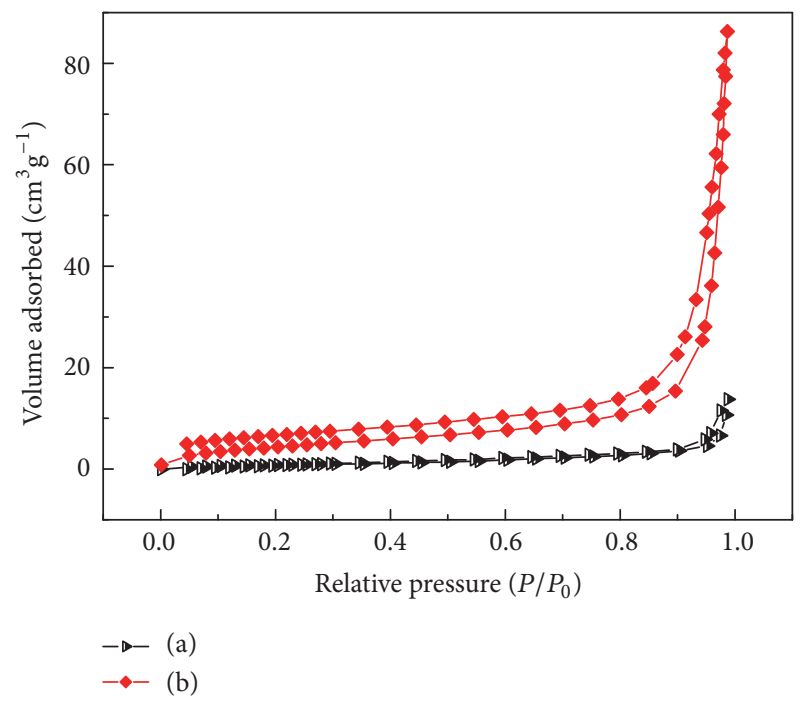

FIgURE 5: Nitrogen sorption isotherm of (a) $\mathrm{Fe}(\mathrm{OH})_{3} @ P M M A$ composite microspheres and (b) magnetic microspheres. 


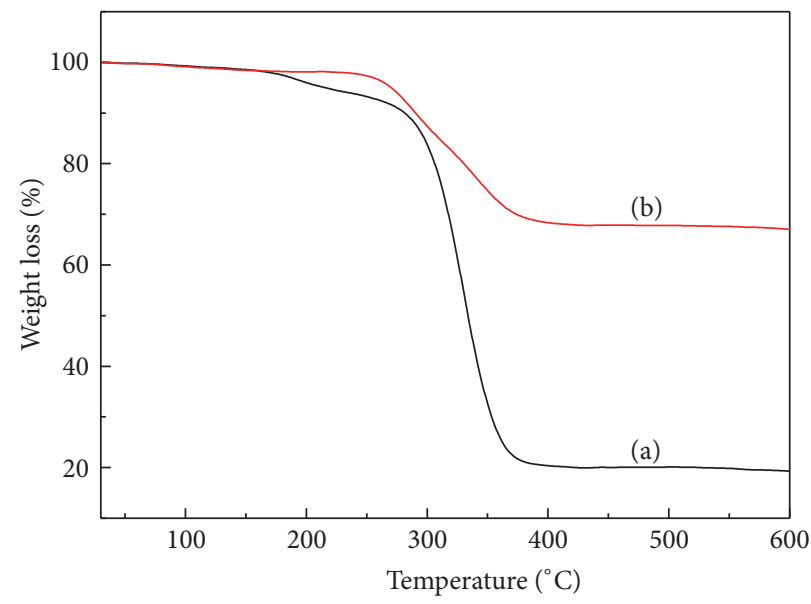

Figure 6: TGA curves of (a) Fe(OH) @PMMA composite microspheres and (b) magnetic microspheres.

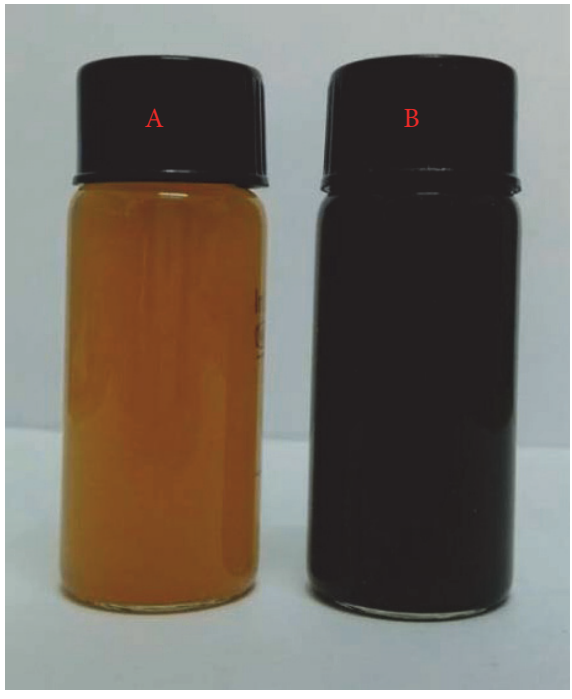

(a)

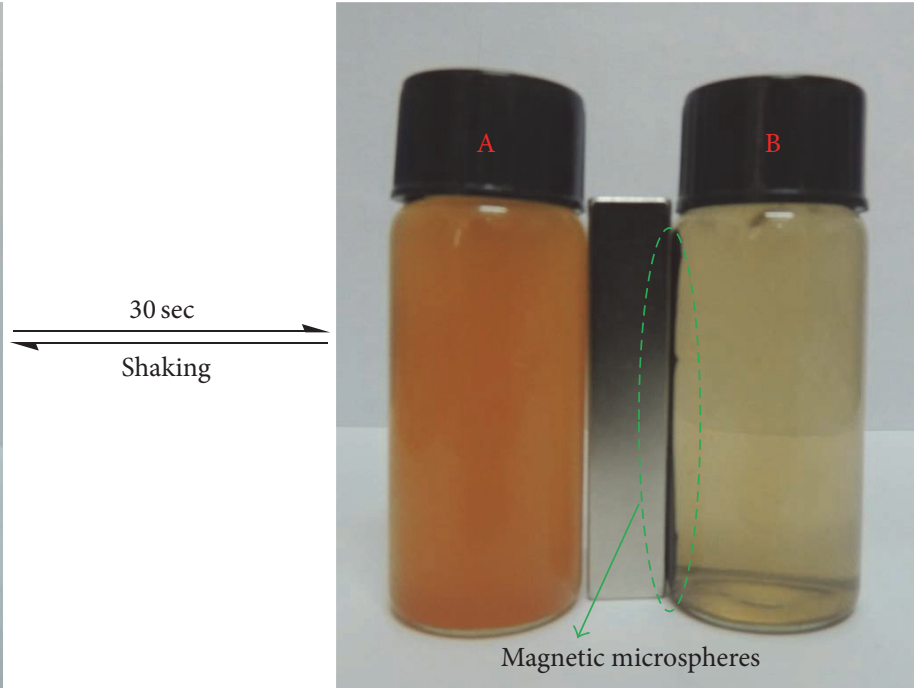

(b)

FIGURE 7: The optical images of the (vial A) Fe(OH) $)_{3} @$ PMMA microspheres and (vial B) magnetic microspheres dispersed in water: (a) before being attracted by a magnet and (b) being attracted by a magnet.

3.6. Magnetic Property Testing. The Fe(OH) 3 @PMMA composite and the magnetic microspheres were dispersed in water by vigorous shaking, respectively; the $\mathrm{Fe}(\mathrm{OH})_{3} @$ PMMA composite results in a brown-colored suspension and it cannot be aggregated in the presence of an external magnetic field [42]. However, the magnetic microspheres result in a black-colored suspension and they could be separated from solution in a short period under an external magnetic field. Once the external magnetic field was evacuated, the magnetic hybrid microspheres can be redispersed into the solution with slight shaking (Figure 7). These results show that magnetic microspheres have been successfully produced; they possess excellent magnetic responsivity and redispersibility, which is of great importance in practical manipulation [30, 43].

3.7. VSM Analysis. The magnetization of samples was evaluated by VSM. Figure 8 shows the magnetization curve of $\mathrm{Fe}(\mathrm{OH})_{3} @ \mathrm{PMMA}$ composite microspheres and magnetic microspheres, respectively. It can be seen that the $\mathrm{Fe}(\mathrm{OH})_{3} @ \mathrm{PMMA}$ composite microspheres (Figure 8(a)) almost have no magnetism, but after calcining, they possessed a characteristic of paramagnetic with the saturation magnetization value of about $32.82 \mathrm{emu} / \mathrm{g}$. They also exhibited superparamagnetism at room temperature because of no hysteresis and remanence (Figure 8(b)) [44].

\section{Conclusions}

In conclusion, we have successfully prepared the magnetic microspheres with diameters in the range of $150-300 \mathrm{~nm}$. TEM results demonstrated that the obtained magnetic microspheres have a novel yolk-shell structure and were well monodispersed. The magnetic microspheres exhibited the feature of polycrystalline, increased BET surface area, and the high 


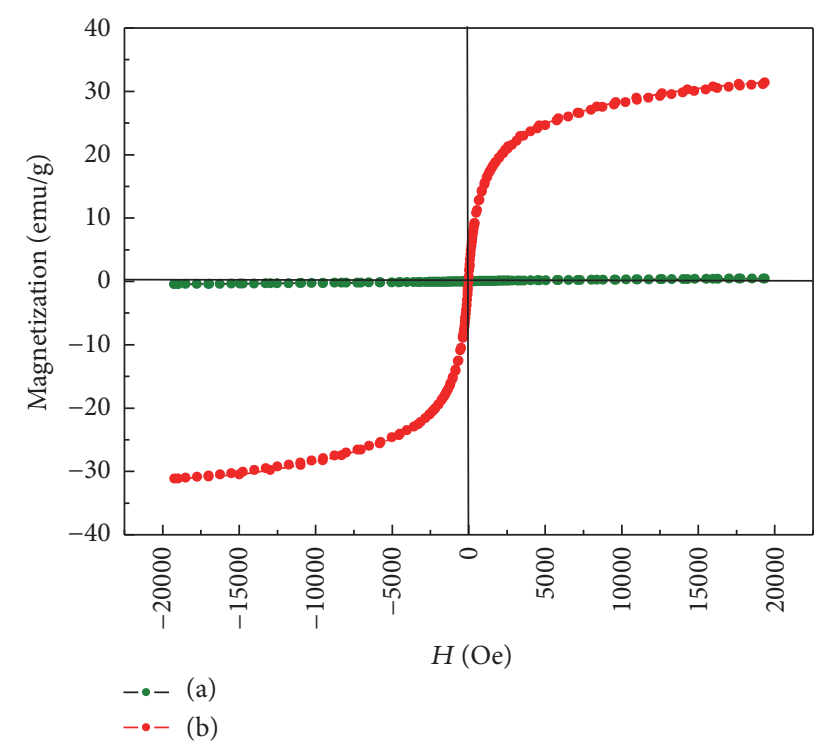

FIGURE 8: Room temperature hysteresis curves of magnetite with (a) $\mathrm{Fe}(\mathrm{OH})_{3} @ \mathrm{PMMA}$ composite microspheres and (b) magnetic microspheres.

magnetic saturation. Taking into account the suitable size, special structure, and good hydrophilic and biocompatible properties, the magnetic microspheres will have wide applications in biomedical fields such as targeted drug delivery, biomolecular separations, cancer treatment, and magnetic resonance imaging.

\section{Competing Interests}

The authors declare that there is no conflict of interests regarding the publication of this paper.

\section{Acknowledgments}

This work was supported by the National Natural Science Foundation of China (11475112) and Programs Foundation of Ministry of Education of China (20130073120051).

\section{References}

[1] F. Lan, Y. Wu, H. Hu, L. Xie, and Z. Gu, "Superparamagnetic $\mathrm{Fe}_{3} \mathrm{O}_{4} /$ PMMA composite nanospheres as a nanoplatform for multimodal protein separation," RSC Advances, vol. 3, no. 5, pp. 1557-1563, 2013.

[2] C. Velez, I. Torres-Díaz, L. Maldonado-Camargo, C. Rinaldi, and D. P. Arnold, "Magnetic assembly and cross-linking of nanoparticles for releasable magnetic microstructures," ACS Nano, vol. 9, no. 10, pp. 10165-10172, 2015.

[3] A. Yakar, G. Tansık, T. Keskin, and U. Gündüz, "Tailoring the magnetic behavior of polymeric particles for bioapplications," Journal of Polymer Engineering, vol. 33, no. 3, pp. 265-274, 2013.

[4] A. Cervadoro, M. Cho, J. Key et al., "Synthesis of multifunctional magnetic nanoflakes for magnetic resonance imaging, hyperthermia, and targeting," ACS Applied Materials \& Interfaces, vol. 6, no. 15, pp. 12939-12946, 2014.
[5] B. J. Park, F. F. Fang, and H. J. Choi, "Magnetorheology: materials and application," Soft Matter, vol. 6, no. 21, pp. 5246-5253, 2010.

[6] K. R. Hurley, H. L. Ring, H. Kang, N. D. Klein, and C. L. Haynes, "Characterization of magnetic nanoparticles in biological matrices," Analytical Chemistry, vol. 87, no. 23, pp. 11611-11619, 2015.

[7] C. Wan and J. Li, "Facile synthesis of well-dispersed superparamagnetic $\gamma-\mathrm{Fe}_{2} \mathrm{O}_{3}$ nanoparticles encapsulated in three-dimensional architectures of cellulose aerogels and their applications for $\mathrm{Cr}(\mathrm{VI})$ removal from contaminated water," ACS Sustainable Chemistry \& Engineering, vol. 3, no. 9, pp. 2142-2152, 2015.

[8] S. K. Suh, K. Yuet, D. K. Hwang, K. W. Bong, P. S. Doyle, and T. A. Hatton, "Synthesis of nonspherical superparamagnetic particles: in situ coprecipitation of magnetic nanoparticles in microgels prepared by stop-flow lithography," Journal of the American Chemical Society, vol. 134, no. 17, pp. 7337-7343, 2012.

[9] L.-K. Shen, K.-H. Fan, T.-L. Wu et al., "Fabrication and magnetic testing of a poly-L-lactide biocomposite incorporating magnetite nanoparticles," Journal of Polymer Engineering, vol. 34, no. 3, pp. 231-235, 2014.

[10] J. Liu, R. Che, H. Chen et al., "Microwave absorption enhancement of multifunctional composite microspheres with spinel $\mathrm{Fe}_{3} \mathrm{O}_{4}$ cores and anatase $\mathrm{TiO}_{2}$ shells," Small, vol. 8, no. 8, pp. 1214-1221, 2012.

[11] S. Chuayjuljit, N. Sukasem, and A. Boonmahitthisud, "Effects of silica, poly(methyl methacrylate) and poly(methyl methacrylate)-grafted-silica nanoparticles on the physical properties of plasticized-poly(vinyl chloride)," Polymer-Plastics Technology and Engineering, vol. 53, no. 2, pp. 116-122, 2014.

[12] A. R. Mahdavian, Y. Sehri, and H. Salehi-Mobarakeh, "Nanocomposite particles with core-shell morphology II. An investigation into the affecting parameters on preparation of $\mathrm{Fe}_{3} \mathrm{O}_{4}$ poly (butyl acrylate-styrene) particles via miniemulsion polymerization," European Polymer Journal, vol. 44, no. 8, pp. 24822488, 2008.

[13] A. Kumari, S. K. Yadav, and S. C. Yadav, "Biodegradable polymeric nanoparticles based drug delivery systems," Colloids and Surfaces B: Biointerfaces, vol. 75, no. 1, pp. 1-18, 2010.

[14] H. Ahmad, K. Kumar, M. A. Rahman et al., "Preparation and characterization of conducting polyaniline layered magnetic nano composite polymer particles," Polymers for Advanced Technologies, vol. 24, no. 8, pp. 740-746, 2013.

[15] Z. Shi, Z. Zhang, R. Fan et al., "Synthesis and characterization of iron particles hosted in Porous Alumina," Journal of Inorganic and Organometallic Polymers and Materials, vol. 21, no. 4, pp. 836-840, 2011.

[16] N.-N. Song, H.-T. Yang, H.-L. Liu et al., "Exceeding natural resonance frequency limit of monodisperse $\mathrm{Fe}_{3} \mathrm{O}_{4}$ nanoparticles via superparamagnetic relaxation," Scientific Reports, vol. 3, article 3161, 2013.

[17] M. Gunay, H. Kavas, and A. Baykal, "Simple polyol route to synthesize heptanoic acid coated magnetite $\left(\mathrm{Fe}_{3} \mathrm{O}_{4}\right)$ nanoparticles," Materials Research Bulletin, vol. 48, no. 3, pp. 1296-1303, 2013.

[18] K. Zhang, W. Wu, K. Guo, J.-F. Chen, and P.-Y. Zhang, "Magnetic polymer enhanced hybrid capsules prepared from a novel Pickering emulsion polymerization and their application in controlled drug release," Colloids and Surfaces A: Physicochemical and Engineering Aspects, vol. 349, no. 1-3, pp. 110-116, 2009.

[19] H. Alamri, N. Ballot, J. Long et al., "Integrative synthesis of coordination polymers, metal oxides, and alloys magnetic nanoparticles in MSU mesoporous silica," Chemistry of Materials, vol. 26, no. 2, pp. 875-885, 2014. 
[20] M. Eid and A. Mansour, "Preparation and magnetic investigation of magnetic nanoparticles entrapped hydrogels and its possible use as radiation shield," Journal of Inorganic and Organometallic Polymers and Materials, vol. 23, no. 6, pp. 12551265, 2013.

[21] M. Faraji, Y. Yamini, and M. Rezaee, "Magnetic nanoparticles: synthesis, stabilization, functionalization, characterization, and applications," Journal of the Iranian Chemical Society, vol. 7, no. 1, pp. 1-37, 2010.

[22] T. Seckin, S. Vural, and S. Köytepe, "Preparation and structural properties of $\mathrm{Fe}_{3} \mathrm{O}_{4}$-polyimide hybrid nanocomposites," Polymer Bulletin, vol. 64, no. 2, pp. 115-126, 2010.

[23] A. B. Rajput, S. J. Rahaman, G. Sarkhel, M. K. Patra, S. R. Vadera, and N. N. Ghosh, "Preparation, characterization and properties of flexible magnetic nanocomposites of $\mathrm{NiFe}_{2} \mathrm{O}_{4}{ }^{-}$ polybenzoxazine-LLDPE," Polymer-Plastics Technology and Engineering, vol. 52, no. 11, pp. 1097-1105, 2013.

[24] J. Hu, M. Chen, and L. Wu, "Organic-inorganic nanocomposites synthesized via miniemulsion polymerization," Polymer Chemistry, vol. 2, no. 4, pp. 760-772, 2011.

[25] M. Ashjari, A. R. Mahdavian, N. G. Ebrahimi, and Y. Mosleh, "Efficient dispersion of magnetite nanoparticles in the polyurethane matrix through solution mixing and investigation of the nanocomposite properties," Journal of Inorganic and Organometallic Polymers and Materials, vol. 20, no. 2, pp. 213-219, 2010.

[26] S. Xuan, F. Wang, J. M. Y. Lai et al., "Synthesis of biocompatible, mesoporous $\mathrm{Fe}_{3} \mathrm{O}_{4}$ nano/microspheres with large surface area for magnetic resonance imaging and therapeutic applications," ACS Applied Materials \& Interfaces, vol. 3, no. 2, pp. 237-244, 2011.

[27] Q. Yang, Y. Wu, F. Lan et al., "Hollow superparamagnetic PLGA/ $\mathrm{Fe}_{3} \mathrm{O}_{4}$ composite microspheres for lysozyme adsorption," Nanotechnology, vol. 25, no. 8, Article ID 085702, 2014.

[28] R. Y. Hong, B. Feng, X. Cai et al., "Double-miniemulsion preparation of $\mathrm{Fe}_{3} \mathrm{O}_{4} /$ poly(methyl methacrylate) magnetic latex," Journal of Applied Polymer Science, vol. 112, no. 1, pp. 89-98, 2009.

[29] P. Xiao, J. J. Zhang, Z. Q. Wang, and H. Lin, "Photon conversion and radiation synergism in $\mathrm{Eu} / \mathrm{Tb}$ complexes incorporated poly methyl methacrylate," Advances in Materials Science and Engineering, vol. 2016, Article ID 2618253, 11 pages, 2016.

[30] J. A. Medford, J. W. Hubbard, F. Orange, M. J.-F. Guinel, B. O. Calcagno, and C. Rinaldi, "Magnetothermal repair of a PMMA/ iron oxide magnetic nanocomposite," Colloid and Polymer Science, vol. 292, no. 6, pp. 1429-1437, 2014.

[31] L. Li, T. Wang, L. Zhang, Z. Su, C. Wang, and R. Wang, "Selected-control synthesis of monodisperse $\mathrm{Fe}_{3} \mathrm{O}_{4} @ \mathrm{C}$ core-shell spheres, chains, and rings as high-performance anode materials for lithium-ion batteries," Chemistry - A European Journal, vol. 18, no. 36, pp. 11417-11422, 2012.

[32] Y. Du, W. Liu, R. Qiang et al., "Shell thickness-dependent microwave absorption of core-shell $\mathrm{Fe}_{3} \mathrm{O}_{4} @ \mathrm{C}$ composites," ACS Applied Materials and Interfaces, vol. 6, no. 15, pp. 12997-13006, 2014.

[33] L. Li, Y. Feng, Y. Li, W. Zhao, and J. Shi, " $\mathrm{Fe}_{3} \mathrm{O}_{4}$ core/layered double hydroxide shell nanocomposite: versatile magnetic matrix for anionic functional materials," Angewandte ChemieInternational Edition, vol. 48, no. 32, pp. 5888-5892, 2009.

[34] C. C. Zhang, X. Li, Y. Yang, and C. Wang, "Polymethylmethacrylate $/ \mathrm{Fe}_{3} \mathrm{O}_{4}$ composite nanofiber membranes with ultra-low dielectric permittivity," Applied Physics A: Materials Science \& Processing, vol. 97, no. 2, pp. 281-285, 2009.
[35] J. Shen, K. Chen, L. Li, W. Wang, and Y. Jin, "Fabrication and microwave absorbing properties of (Z-type barium ferrite/ silica)@polypyrrole composites," Journal of Alloys and Compounds, vol. 615, pp. 488-495, 2014.

[36] W. Cheng, K. Tang, Y. Qi, J. Sheng, and Z. Liu, “One-step synthesis of superparamagnetic monodisperse porous $\mathrm{Fe}_{3} \mathrm{O}_{4}$ hollow and core-shell spheres," Journal of Materials Chemistry, vol. 20, no. 9, pp. 1799-1805, 2010.

[37] B. J. Park, M. K. Hong, and H. J. Choi, “Atom transfer radical polymerized PMMA/magnetite nanocomposites and their magnetorheology," Colloid and Polymer Science, vol. 287, no. 4, pp. 501-504, 2009.

[38] H. Kavas, M. Günay, A. Baykal, M. S. Toprak, H. Sozeri, and B. Aktaş, "Negative permittivity of polyaniline- $\mathrm{Fe}_{3} \mathrm{O}_{4}$ nanocomposite," Journal of Inorganic and Organometallic Polymers and Materials, vol. 23, no. 2, pp. 306-314, 2013.

[39] L. Chen, Q. Zhou, Q. Xiong, W. Li, J. Liu, and X. Yang, "Shapeevolution and growth mechanism of $\mathrm{Fe}_{3} \mathrm{O}_{4}$ polyhedrons," Advances in Materials Science and Engineering, vol. 2015, Article ID 763124, 7 pages, 2015.

[40] M. Shao, F. Ning, J. Zhao, M. Wei, D. G. Evans, and X. Duan, "Preparation of $\mathrm{Fe}_{3} \mathrm{O}_{4} @ \mathrm{SiO}_{2} @$ layered double hydroxide coreshell microspheres for magnetic separation of proteins," Journal of the American Chemical Society, vol. 134, no. 2, pp. 1071-1077, 2012.

[41] K. Zhang, J. Y. Lim, and H. J. Choi, "Amino functionalization and characteristics of multi-walled carbon nanotube/poly(methyl methacrylate) nanocomposite," Diamond and Related Materials, vol. 18, no. 2-3, pp. 316-318, 2009.

[42] Y. Tan, Z. Zhuang, Q. Peng, and Y. Li, "Room-temperature soft magnetic iron oxide nanocrystals: synthesis, characterization, and size-dependent magnetic properties," Chemistry of Materials, vol. 20, no. 15, pp. 5029-5034, 2008.

[43] F. F. Fang, J. H. Kim, and H. J. Choi, "Synthesis of core-shell structured $\mathrm{PS} / \mathrm{Fe}_{3} \mathrm{O}_{4}$ microbeads and their magnetorheology," Polymer, vol. 50, no. 10, pp. 2290-2293, 2009.

[44] S. Kanagesan, M. Hashim, S. Tamilselvan et al., "Synthesis, characterization, and cytotoxicity of iron oxide nanoparticles," Advances in Materials Science and Engineering, vol. 2013, Article ID 710432, 7 pages, 2013. 

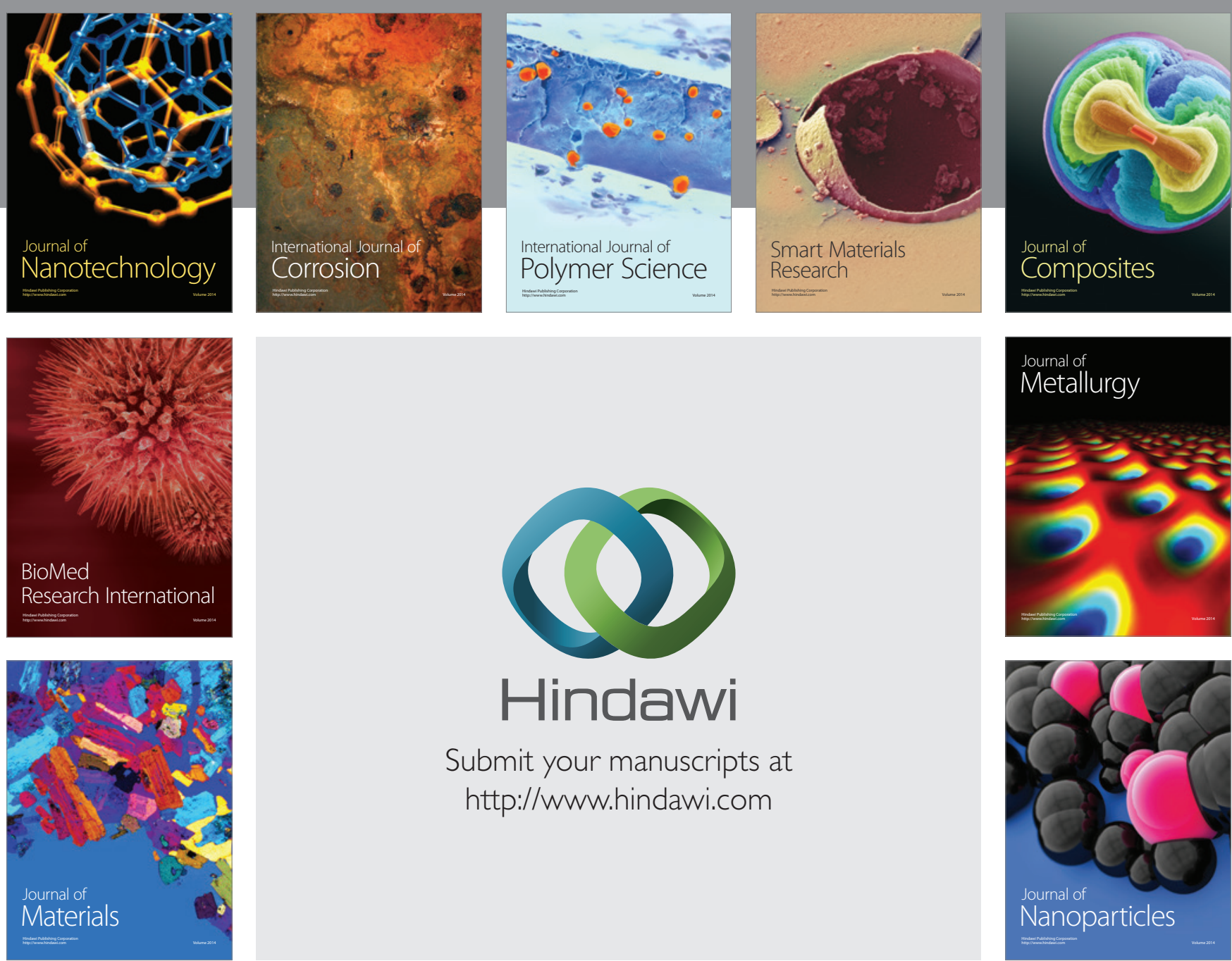

\section{Hindawi}

Submit your manuscripts at

http://www.hindawi.com

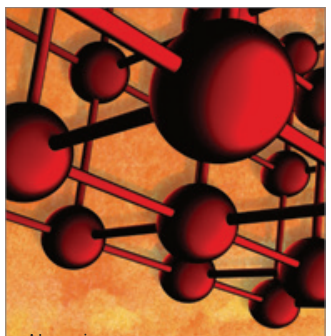

Materials Science and Engineering
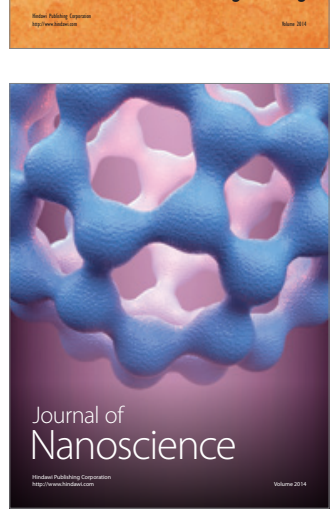
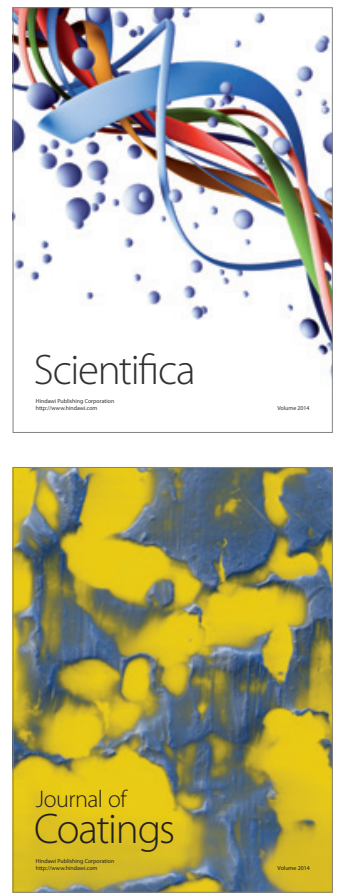
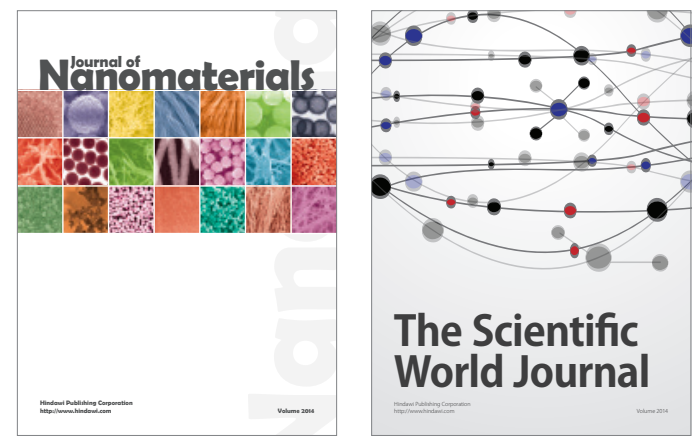

The Scientific World Journal
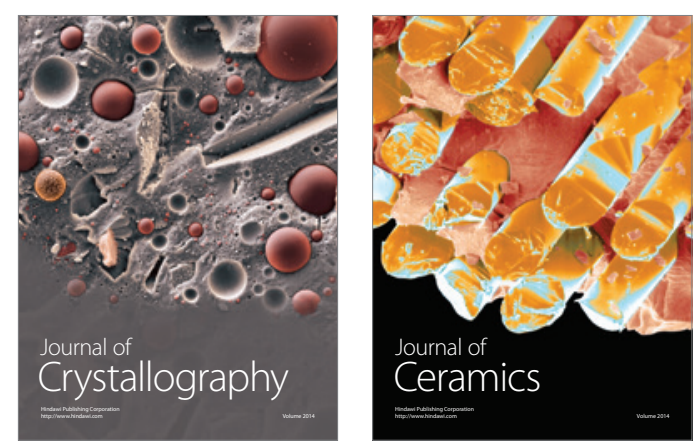
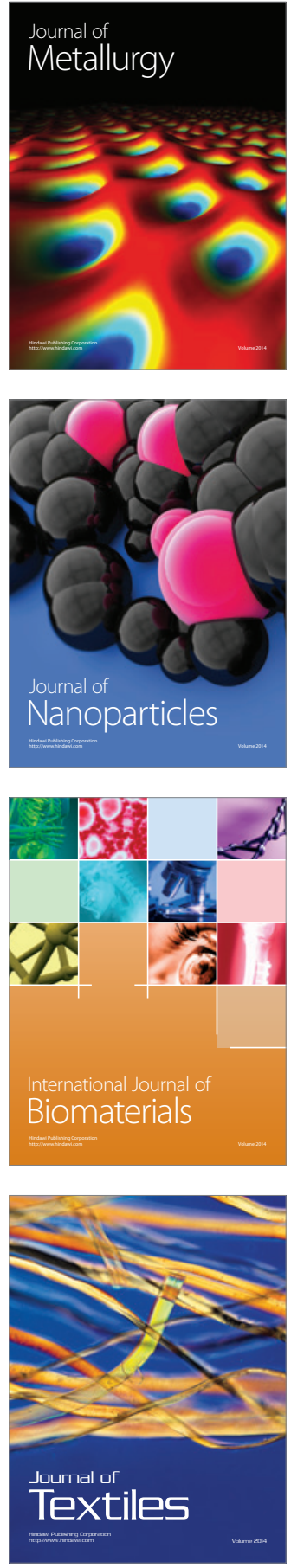